\title{
Abdominal bilgisayarlı tomografi görüntülerinde böbrek taşlarının sınırlarının ve sayılarının görüntü işleme yöntemleri kullanılarak tespiti.
}

\section{The detection of the borders and numbers of kidney stones in the abdominal computed tomography images using image processing methods.}

\author{
Merve Karaman $^{1 *}$ (D), Salim Çınar² (D) \\ ${ }^{1}$ Niğde Ömer Halisdemir Üniversitesi, Elektrik Elektronik Mühendisliği, 51240, Niğde, Türkiye
}

\begin{abstract}
Özet
Böbrek taşlarının medikal görüntülerdeki teşhisi ve tespiti hastalığın seyri ve tedavi yönteminin belirlenmesi açısından önemlidir. Abdominal Bilgisayarlı Tomografi (BT) görüntülerinin gürültülü ve düşük çözünürlükte olması böbrek taşı teşhisini zorlaştıran faktörlerdir. Bu çalışmada abdominal BT görüntülerinde bulunan böbreklerdeki taşların sınırlarının ve sayılarının belirlenmesi amaçlanmıştır. İlk olarak BT görüntülerinin netleştirilmesi ve gürültünün yok edilmesi için Gama Düzeltmesi yöntemi kullanılmıştır. İkinci olarak böbrekler, ilgi bölgesi (ROI: Region of Interest) yöntemi ile manuel olarak seçilmiştir. Seçilen böbrek bölgelerinde eşikleme uygulanarak böbrek taşlarının tespiti gerçekleştirilmiştir. Böbrek sınırları içerisinde bulunan taşlara Morfolojik aşındırma ve genişletme işlemleri uygulanarak görüntüde bitişik algılanan taşlar ayrıştırılmış ve taşlar sayılmıştır. Çalışmanın başarımının hesaplanması için Hata Matrisi oluşturulmuştur. Önerilen yöntemin performans analizinde Doğruluk (Accuracy), Hassasiyet (Sensivity) ve Özgüllük (Specifity) değerleri sırasıyla \%97, \%96, \%100 şeklinde Hata Matrisi kullanılarak hesaplanmıştır. Elde edilen sonuçlar, kullanılan yöntemin böbrek taşı tespiti ve sayımında başarılı olduğunu göstermektedir.
\end{abstract}

Anahtar kelimeler: Görüntü işleme, Böbrek taşı, ROI, Eşikleme, Morfoloji

\section{Giriș}

Görüntü işleme teknikleri, görüntülerin iyileştirilmesi, görüntü üzerinde bulunan insan algısının görmekte zorlandığı nesnelerin tespiti, farklı nesnelerin ayırt edilmesi ve nesne takibi gibi çok geniş uygulama alanına sahiptir. Medikal bir görüntünün uzman tarafından doğru değerlendirilmesinde düşük çözünürlük ve gürültü kaynaklı bozulmalar bazı problemlerin ortaya çıkmasına sebep olabilmektedir. Bu problemlerin çözümünde görüntü işleme ve iyileştirme teknikleri kullanılarak teşhisin veya tanının kolay ve doğru bir şekilde yapılması sağlanabilir. Örneğin medikal bir görüntüde bulunan lezyon oluşumu görüntü işleme teknikleri ile netleștirilebilmekte ve tespit edilebilmektedir.

Böbrekler normal anatomiye sahip insanlarda çift olarak bulunan organlardır ve görevleri kandaki zararlı maddeleri

\begin{abstract}
The diagnosis and detection of kidney stones in medical images are important in terms of determining disease progression and treatment methods. Noisy and lowresolution Abdominal Computed Tomography (CT) images are factors that complicate the diagnosis of kidney stones. The goal of this study is to determine the borders and number of stones found in the kidney on abdominal CT images. Firstly, the Gamma Correction method is used to sharpen CT images and eliminate noise. Secondly, the kidneys are selected manually using the Region of Interest (ROI) method. The detection of kidney stones is carried out by applying a threshold to the selected kidney regions. By applying morphological erosion and dilation processes to the stones within the limits of the kidney, the stones detected adjacent in the image are separated, and the stones are counted. The confusion matrix is created to calculate the performance of the study. In the performance analysis of the proposed method, the Accuracy, Sensitivity, and Specificity values using the Confusion Matrix are calculated at $97 \%, 96 \%$, and $100 \%$, respectively. The results show that the proposed method is successful in detecting and counting kidney stones.
\end{abstract}

Keywords: Image processing, Kidney stones, ROI, Thresholding, Morphology

filtreleyerek idrar ile dışarı atmaktır. İdrar ile atılamayan ve çözülemeyen maddeler birleşerek böbrek taşı oluşumuna sebep olmaktadır. Böbrek taşı, böbreklere zarar veren ve ilerleyebilen bir hastalıktır. Bu nedenle kalıcı sorunlara yol açmadan önce böbrek taşı tespiti hayati önem taşımaktadır [1].

Böbrek taşları ultrason ya da BT gibi medikal görüntüleme teknikleri kullanılarak görüntülenebilmektedir. BT'nin artan kullanımı taş tespitini iyileştirmiş ve böbrek taşı insidansının artmasına sebep olmuştur [2]. Ancak abdominal BT görüntülerinin düşük çözünürlüğe sahip olması teşhisi ve taşların değerlendirilmesini zorlaştırmaktadır [3].

Literatürde böbrek bölgesinin çıkarılması ve taşların değerlendirilmesine yönelik çeşitli yöntemler bulunmaktadır ve bu alanda çalışmalar devam etmektedir. Saman ve

\footnotetext{
* Sorumlu yazar / Corresponding author: e-posta / e-mail: merve_karaman@ohu.edu.tr (M.Karaman) Gelis / Recieved: 16.06.2021 Kabul / Accepted: 13.08.2021 Yayımlanma / Published: 14.01.2022 doi: 10.28948/ngmuh.953423
} 
Vladimir, abdominal BT'de böbrek taşının saptanması için konum, kontrast ayarı, bölütleme, bağlı bileşen etiketleme, nesne algilama yöntemlerini önermişlerdir [4]. Akkasaligar vd., abdominal BT görüntülerine bazı temel görüntü iyileştirme teknikleri uygulamıştır. Gerçekleştirilen ön işlemenin ardından gri seviye oluşumu 'Fuzzy C- means' yöntemi ile sınıflandırılmış ve böbrek taşı tespiti gerçekleştirilmiştir [5]. Shah ve Kadge, BT görüntülerine ön işleme-morfolojik işlemler, ikili görüntü, eşik bölütleme, taş sayısı, boyutlarının ve konumlarının belirlenmesi biçiminde beş aşamadan oluşan bir yaklaşım uygulamışlardır [3].

Önerilen bu çalışmada abdominal BT görüntülerinde böbrek bölgesinin çıkarılması ve ardından böbrekte bulunan taşlara ait sayı, konum, boyut ve taş ile böbrek merkezi arasındaki Öklid Mesafesi bilgilerinin hesaplanması amaçlanmaktadır. Bu sayede görüntüyü değerlendirecek uzman daha kaliteli bir görüntüyü inceleyerek teşhis ettiği sonuçları, algoritma sonuçları ile karşılaştırarak daha güvenilir verilere ulaşabilecektir.

Böbrek taşlarının boyutu tedavi yönteminin belirlenmesinde önemlidir. Böbrek taşının $2 \mathrm{~cm}$ 'den daha büyük olması durumunda standart olarak Perkütan Nefrolitotomi (PNL) cerrahi tedavi yöntemi uygulanmaktadır [6]. Çalışma sonucunda böbrekte bulunan taşların piksel bazında boyut bilgisi hesaplanmıştır. $\mathrm{Bu}$ sayede uzman böbrek taşı hastalığının tedavisinde izleyeceğ yol hakkında karar vermek için bir ön bilgiye sahip olabilecektir.

Önerilen yöntemin aşamaları sırasıyla şu şekildedir. İlk aşamada görüntünün kontrast ayarı için Gama Düzeltme yöntemi kullanılmıştır. Sadece böbrekte bulunan taşların değerlendirilebilmesi için, böbrek bölgelerinin kullanıcı tarafından seçilmesi sağlanarak ROI çıkarılmıştır. İkinci aşamada çıkarılan ROI'ler eşikleme uygulanarak ikili görüntülere dönüştürülmüş ve morfolojik işlem sonucu elde edilen görüntüde taşların ağırlık merkezi ve piksel alanı hesaplanarak böbrek taşlarının; sayı, boyut, konum ve böbrek merkezine olan Öklid mesafeleri bulunmuştur.

\section{Metot}

Abdominal BT görüntülerinin düşük kontrastlı ve gürültülü olması taş tespitini zorlaştırmaktadır. Bu çalışmada böbrek sınırlarının netleştirilmesi ve gürültülerin bastırılması için Gama Düzeltmesi kullanılmıştır. Gama düzeltmesi sonucu elde edilen görüntüde böbrek sınırları manuel bir serbest çizim ile takip edilerek böbrek bölgeleri ROI'ler belirlenmiştir. Orijinal görüntüden çıkarılan böbrek bölgelerine uygun eşik seviyesi uygulanarak böbrek bölgesi ikili görüntüye dönüştürülmüştür. Göz tespitinde yapışık değerlendirilen taşların ayrılması ve böbrek taşı olmamasına rağmen taş olarak algılanabilecek nesnelerin kaldırılması için ikili görüntüde morfolojik işlemler uygulanmıştır.

Şekil 1'de örnek bir abdominal BT görüntüsü verilmiştir. Görüntüde kemikler ve kalsifiye yapılar yakın ya da eşit yeğinlik (gri seviye) değerlerine sahiptir. Kemik ve kalsifiye yapıların ön plana çıkması ve böbrek sınırlarının daha belirgin olması için görüntünün yoğunluk değerleri bir gama değeri ile ayarlanmıştır. Gama Düzeltmesi $\gamma$ ( Gama) ve $c$ olmak üzere iki değişken ile görüntünün genel parlaklığını kontrol eden histogram değişimine dayalı bir dönüşümdür ve Denklem (1) 'de verilen eşitlik ile ifade edilmektedir [8].

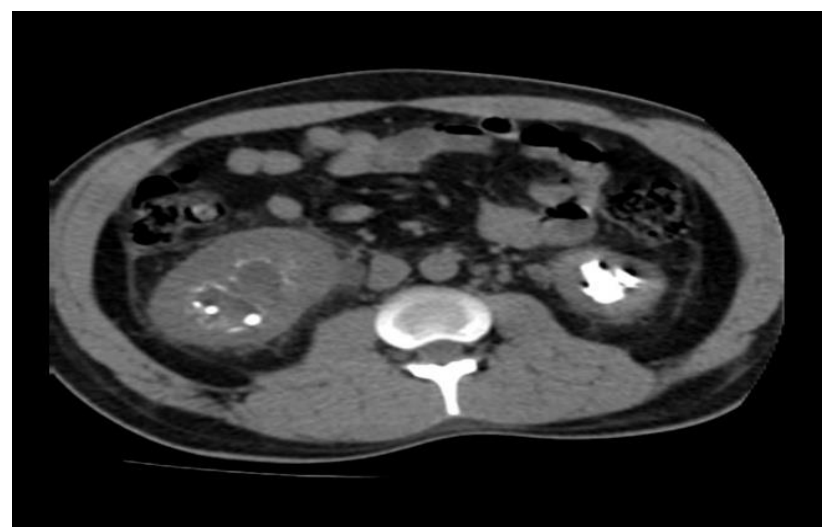

Şekil 1. Abdominal BT görüntüsü [7]

$$
I_{\text {in }}=c I_{\text {out }}^{\gamma}
$$

Burada $I_{\text {in }}$ giriş görüntüsü, $I_{\text {out }}$ çıkış görüntüsüdür. $c$ ve $\gamma$ pozitif sayılardır. Düşük kontrastlı parlak görüntülerin kontrastı arttırmak için uygulanan gama düzeltmesi yönteminde $c=1$ olarak seçilir. Düşük kontrastlı parlak abdominal görüntülerinin karanlık bölgeye çekilmesi için yeğinlik seviyelerinin daraltılması gerekmektedir [8]. Yeğinlik seviyesinin daraltmak için $\gamma>1$ değerleri seçilmelidir. Uygun gama değeri 1'den büyük olmak koşulu ile deneysel çalışmalar ile belirlenebilir. $\mathrm{Bu}$ deneysel çalışmalar ile $\gamma=3$ seçildiğinde beklenildiği gibi taş olmayan nesnelerin bir kısmı atılmıştır ve böbrek sınırları netleştirilmiştir. Gama Düzeltmesi sonucunda giriş ve çıkış görüntülerinin yeğinlik seviyeleri arasında oluşan eğrinin kontrast sınırları [ [0 1] aralığına uyacak şekilde ölçeklenmiştir. Gama Düzeltmesi sonucu karanlık bölgeye çekilen abdominal BT görüntüsünün Şekil 2'de böbrek sınırlarının serbest ROI işlecinin takip edebileceği biçimde netleştirildiği ve yumuşak dokunun gri seviye yeğinlik değerinin karanlık bölgeye çekildiği görülmektedir.

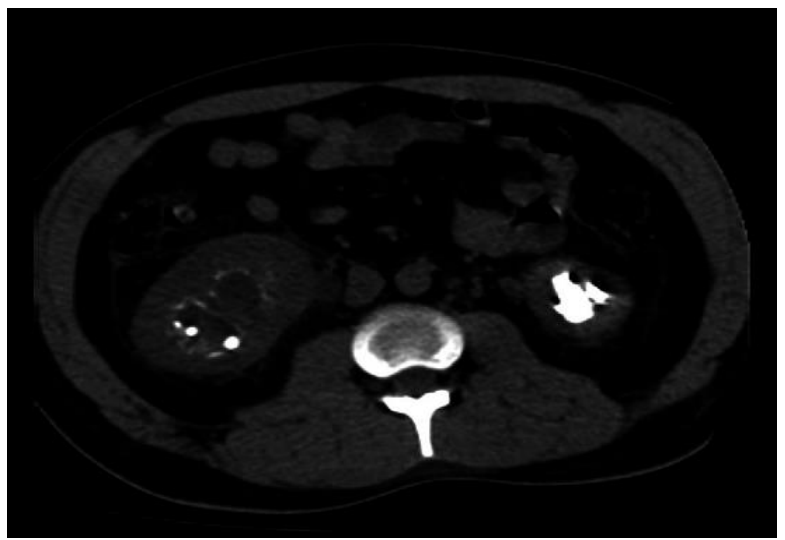

Şekil 2. Gama düzeltmesi uygulanmış abdominal BT görüntüsü

Gama Düzeltmesi uygulanan BT görüntüsünde böbrek bölgeleri, MATLAB görüntü işleme araçları ile manuel 
olarak seçilerek ROI'ler çıkartılır. Bu sayede görüntüde böbrek dışında taşa benzer oluşumlar değerlendirilmemekte ve sadece böbrek içinin incelenmesine olanak sağlanmaktadır. Böbrek bölgesinin nesnesini oluşturmak için kullanılan işlev serbest olarak belirlenen ilgi bölgesinin bir nesnesini oluşturmaktadır. Böbrek bölgesinin kullanıcı tarafından işaretlendiği pencere Şekil 3 'te görülmektedir. İşlev ilk tepe noktasından kenar sınırlarını takip ederek çizim yapmaktadır ve bölge boyunca farklı tepe noktaları yerleştirilebilir. İlk tepe noktasından son tepe noktasına gelindiğinde ilgi bölgesi seçilmektedir.

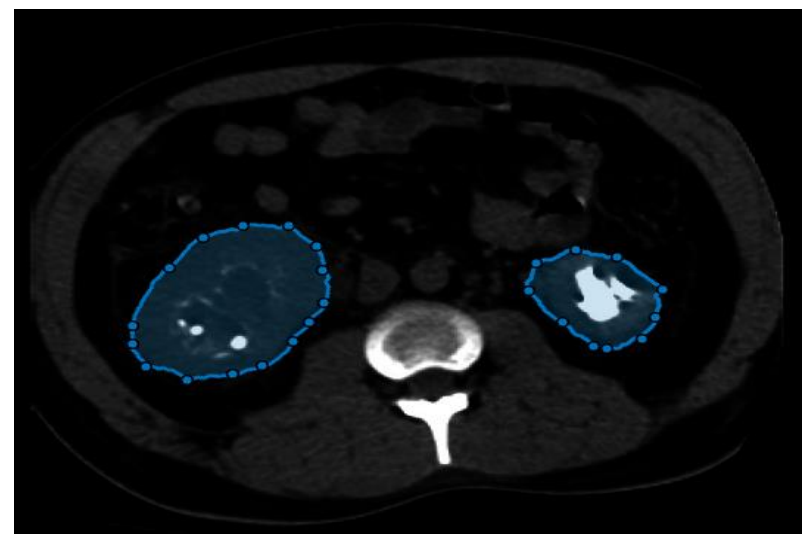

Şekil 3. Böbrek bölgelerinin ROI ile seçilmesi

Böbrek bölgelerinin seçildiği alanlar kesilerek, seçilen böbrek alanlarının aydınlık, arka planın karanlık bölgeyi temsil ettiği ikili bir maske oluşturulur. Maskeleme görüntüde işlem için bir alanı izole etmek için kullanılır ve ROI işleme olarak adlandırılır ve orijinal görüntü ile maske görüntüsü çarpılarak görüntüde istenilen alan izole edilir. Görüntü çarpma işlemi iki veya daha fazla görüntü arasında piksel bazında gerçekleştirilir [9]. Oluşturulan maske ve Gama Düzeltmesi uygulanan görüntünün çarpılması ile sadece böbrekleri içeren görüntü elde edilir. Şekil 4'te abdominal BT görüntülerinde bulunan böbrek dışındaki organlar ve kemikler çıkarılmış yalnızca gri seviye böbrek bölgeleri kalmıştır. Bu sayede sadece ilgilenilen böbrek bölgeleri üzerinde işlem yapılabilmesi sağlanmıştır.

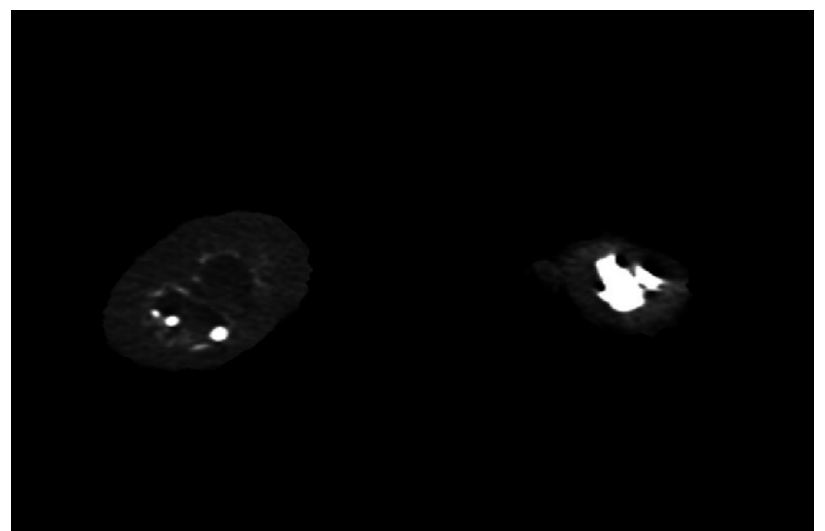

Şekil 4. Gama düzeltmesi uygulanan görüntü ile ikili maske görüntüsünün çarpımı ile elde edilen böbrek bölgeleri
Abdominal BT görüntülerinden çıkarılan böbrek alanlarında taşları temsil eden piksellerin belirlenmesi için eşik değerinin uygulanması gerekmektedir. Literatürde yapılan çalışmalarda [3] ve önerilen bu çalışmada deneysel sonuçlara göre ' $T$ ' eşik seviyesi olmak üzere $T \geq 200$ değerinde eşikleme sonucunun daha iyi performans sergilediği görülmüştür. Bu eşik seviyesi, çıkarılan böbrek bölgelerine uygulandığında yumuşak dokular atılarak görüntüde sadece taşlar kalmaktadır. Böbrek bölgelerinin gri seviye olduğu Şekil 4'teki görüntüye belirlenen eşik değeri $T=200$ uygulanmıştır Taşların ön planda, böbrek yumuşak dokusunun arka planda kaldığı taş sınırlarının korunması ile elde edilen ikili görüntü Şekil 5 'te gösterilmiştir.

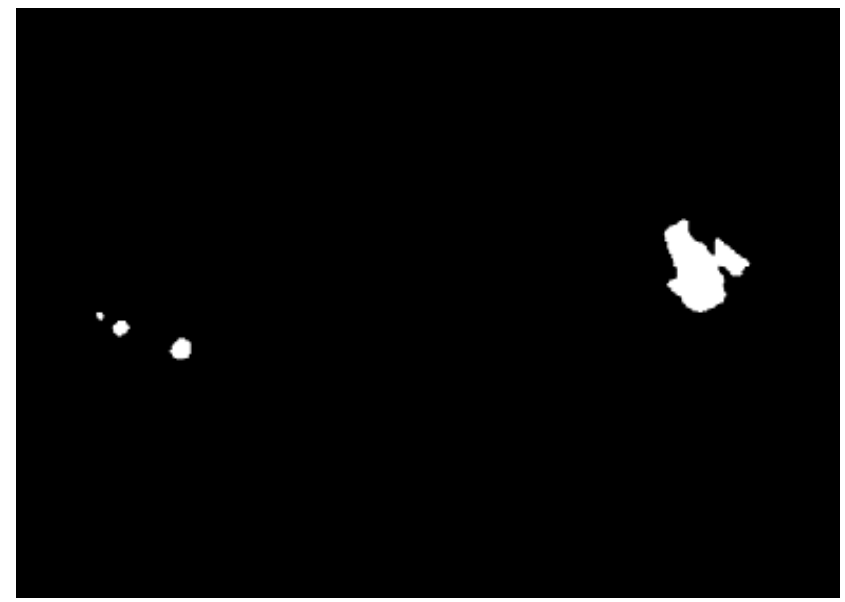

Şekil 5. Eşikleme sonucu elde edilen ikili görüntü

İkili görüntüde 8-bağlı pikselleri nesne olarak tanımlayan ve bu nesnelerin dış sınırlarını takip eden komut bwboundaries kullanılarak bu sınırlar içerisinde kalan nesnelerin sayıs1, konumu ve boyutu hesaplanabilmektedir. İlk olarak nesnelerin sınırları izlenerek bir değişkene atanmıştır. Bu değişkenin boyut uzunluğu böbrekte bulunan taş sayısını vermektedir. Yapılan çalışmada böbreklerin ayrı ayrı seçilmesi sonucu taş sayıları da her böbrek için ayrı hesaplanmaktadir.

Bulunan her taşın piksel bazında alanları hesaplanmıştır. Görüntülerin gerçek boyut bilgisinin olduğu verilerde metrik hesaplamalar ile $\mathrm{mm}$ cinsinden taş boyutu hesaplanabilir. Ancak çalışmada kullanılan veri setinde görüntülerin gerçek boyut bilgisinin olmaması sebebiyle metrik hesap yapılamamıştır ve taşların alanları piksel bazında hesaplanmıştır.

Manuel olarak seçilen böbrek bölgeleri ile oluşturulan maske, böbrek alanlarının beyaz (lojik 1), böbrek dışındaki alanların siyah (lojik 0) olduğu bir ikili görüntüdür. Bu ikili görüntüde böbrek alanları birer nesne olarak değerlendirilir. Benzer şekilde eşikleme sonucu elde edilen görüntüde taşlar beyaz arka plan siyahtır. Böbrek bölgelerinin olduğu ikili görüntü ve Şekil 5'te görülen yalnızca taşların kaldığı ikili görüntüde regionprops kullanılarak böbrek ve taşlara ait alan ve ağırlık merkezleri hesaplanmıştır. Kullanılan komutta hesaplanması istenilen parametreler ikili görüntüdeki nesnelerin (böbrek ve taşlar) alan hesabı için Area, ağırlık merkezi koordinatları için ise Centroid olarak belirlenmiştir. 
Alan hesabı için kullanılan özellik Area ilgili bölgede gerçek piksel sayısını skaler olarak hesaplamaktadır. Böbrek ve taşların ağırlık merkezinin koordinat hesabında kullanılan Centroid parametresi $1 x Q$ 'luk vektör içerisine ağırlık merkezi noktasına ait koordinatları atar. Vektörün ilk elemanı yatay koordinat $(x)$ değerini, ikinci elemanı ise dikey koordinat $(y)$ değerini taşımaktadır.

Son aşamada böbrek ağırlık merkezleri ile ilgili böbrekte bulunan taşların ağırlık merkezleri arasındaki Öklid uzaklığı hesaplanmıştır. Öklid hesabı farklı nesneler arasındaki uzaklığı, benzerliği değerlendirmek için kullanılan bir yöntemdir. Böbrek ağırlık merkezi ile ilgili böbrekte bulunan taşların ağırlık merkezleri arasındaki Öklid uzaklığına ait matematiksel ifadesi Denklem (2)'de verilmiştir $[10,11]$.

$$
D=\sqrt{\left(x_{1}-x_{2}\right)^{2}-\left(y_{1}-y_{2}\right)^{2}}
$$

Burada $D$ Öklid Mesafesi, $\left(x_{1}, y_{1}\right)$ böbrek bölgesinin ağırlık merkezi koordinatı ve $\left(x_{2}, y_{2}\right)$ taşların ağırlık merkezi koordinatıdır. Denklem (2) ile böbrek taşlarının ve böbrek alanlarının ağırlık merkezleri arasındaki Öklid hesabı yapılmıştır.

Üzerinde çalışılan veri setinde bulunan görüntülerin farklı parlaklık seviyelerine sahip olması ve düşük çözünürlük sebebiyle bazı taşlar bitişik değerlendirilmektedir. Örneğin bir böbreğinde 4 adet böbrek taşı olan hastaya ait görüntüde parlaklık seviyesinin yüksek olması sebebiyle eşikleme sonucu bitişik değerlendirilen gerçekte 4 adet olan taş algoritmada 1 taş olarak sayılmaktadır. Problem çözümü için matematiksel morfoloji önerilmiştir. Aşındırma, genişletme ve morfolojik filtreleme gibi teknikler görüntüdeki sınırları, iskeletleri ve dışbükey zarf gibi bölgesel şekillerin tanımı için görüntü bileşenlerini elde etmede kullanılan matematiksel morfoloji teknikleridir [9]. Görüntüde morfolojik işlem uygulanmak istenen özellikler için görüntüyü ifade edebilecek alt görüntüler veya küçük kümeler yapısal elemanlardır. Buna göre aşındırma işleminin matematiksel ifadesi Denklem (3)’te verilmiştir. Yapısal elemanın biçim ve boyutu deneysel olarak belirlenebilmektedir. Yapılan çalışmada aşındırma ve genişletme yöntemlerinde alt küme olarak disk şeklinde $r=$ 3 yarıçaplı bir yapısal eleman belirlenmiştir. Bitişik taşları ayıracak ve aynı zamanda küçük taşları kaybetmeyecek biçimde optimum yapısal eleman biçimi ve büyüklüğü deneysel sonuçlar ile belirlenmiştir. Böbrek bölgesinin çıkarılması, eşikleme ardından oluşan, yalnızca taşların bulunduğu ikili görüntüde bitişik değerlendirilen taşlar arasındaki küçük bağları koparmak için öncelikle $r=3$ yarıçaplı disk şeklinde bir yapısal elemanla aşındırma işlemi gerçekleştirilmiştir. $\mathrm{Bu}$ sayede taşlar incelmiş ve bitişik olanlar koparılmıştır.

$$
A \Theta B=\left\{z \mid(B)_{z} \subseteq A\right\}
$$

Denklem (3)'te $A$ morfolojik işlem uygulanacak görüntü $B$ ise $A$ 'nın alt kümesidir. $A$ görüntüsünü $B$ yapısal elemanı ile aşındırma işlemi $B$ 'nin $A$ içerisinde yer alması koşulunun, görüntü arkaplanı ile ortak elemana sahip olmaksızın $B$ 'ye eşit olması biçiminde ifade edilebilir [9].

Aşındırma işleminin ardından taş alanlarının doğru değerlendirilebilmesi için erozyon işleminde kullanılan yapısal eleman kullanılarak genişletme işlemi gerçekleştirilmiştir. Genişletme işlemi aşındırma işleminin tersi gibi düşünülebilir. Yani aşındırmada görüntüdeki nesneler aşınarak incelirken, genişletme işleminde nesneler genişleyerek büyür. Denklem (4) genişletme işleminin matematiksel ifadesini vermektedir.

$$
A \oplus B=\left\{z \mid\left[(\widehat{B})_{z} \cap A\right] \subseteq A\right\}
$$

Burada $\hat{B}, B$ 'nin kendi orjinine göre yansımasının $Z$ kadar kaydırılmasıdır. $A$ 'nın $\hat{B}$, ile genişletilmesi, $\hat{B}$ 'nin A ile en az bir elemanı çakışacak şekilde tüm $z$ kaymaları için bulunan sonuçları içeren bir küme olarak tanımlanabilir [9].

Şekil 6'da morfolojik işlem uygulanmadan öncesi ve sonrası elde edilen sonuç görüntüsü verilmiştir. Şekil 6 (a)' da görüldüğü gibi 8-bağlı pikseller ile nesne bir bütün olarak değerlendirilmekte ve bitişik nesnenin sınırları takip edilerek sayıldığında böbrek taşı sadece bir taş olarak sayılmaktadır. Bunun sebebi böbrek bölgesine eşikleme uygulandığında bu eşik seviyesine sahip birkaç piksellik gürültülerin ayrık taşlar arasında zayıf bir bağ oluşturmasıdır. Şekil 6 (b)'de morfolojik aşındırma ve genişletme işlemleri uygulanmasının ardından bitişik taşlarda zayıf bağların koparıldığı ve ayrı ayrı nesne biçiminde değerlendirilebilir olduğu gösterilmektedir.

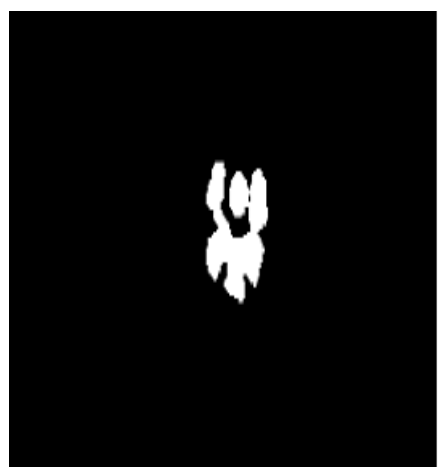

(a)

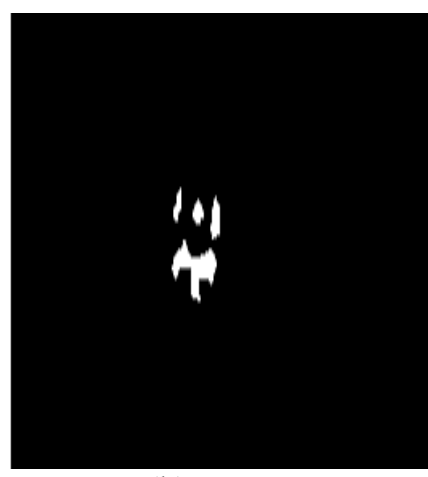

(b)
Şekil 6. (a) Morfolojik işlem öncesi bitişik taşlar (b)Morfolojik işlem sonrası ayrıştırılan taşlar

\section{Materyal}

Yapılan çalışmada 20 hastaya ait abdominal BT görüntülerinden oluşan veri seti kullanılmıştır. Veri seti bilateral veya tek taraflı böbrek taşı oluşumlarına sahip ve böbrek taşı olmayan hastalara ait görüntülerden oluşmaktadır $[12,13]$. Veri seti yaş ortalaması 40 olan kadın ve erkek hastalara ait abdominal BT görüntülerinden oluşmaktadır.

Görüntülerde görsel inceleme sonucu elde edilen her bir hastaya ait sağ ve sol böbreklerde bulunan taşların sayıları Tablo 1'de verilmiştir. Veri seti bilateral, tek taraflı, çoklu ve bir taşa sahip hastalardan alınan görüntülerden oluşmaktadır. 
Tablo 1. Böbreklerde tespit edilen taşların sayısı

\begin{tabular}{|c|c|c|}
\hline \multirow[t]{2}{*}{ Hasta } & \multicolumn{2}{|c|}{ Taş Sayısı } \\
\hline & Sol Böbrek & Sağ Böbrek \\
\hline 1 & 1 & 0 \\
\hline 2 & 0 & 0 \\
\hline 3 & 1 & 1 \\
\hline 4 & 1 & 0 \\
\hline 5 & 3 & 1 \\
\hline 6 & 1 & 4 \\
\hline 7 & 0 & 0 \\
\hline 8 & 1 & 0 \\
\hline 9 & 1 & 1 \\
\hline 10 & 1 & 1 \\
\hline 11 & 0 & 0 \\
\hline 12 & 2 & 2 \\
\hline 13 & 4 & 3 \\
\hline 14 & 0 & 1 \\
\hline 15 & 1 & 2 \\
\hline 16 & 2 & 3 \\
\hline 17 & 0 & 0 \\
\hline 18 & 3 & 2 \\
\hline 19 & 0 & 0 \\
\hline 20 & 1 & 0 \\
\hline
\end{tabular}

\section{Sonuçlar}

$\mathrm{Bu}$ bölümde abdominal BT görüntülerinde böbreklerde bulunan taşların tespitine ilişkin incelemeler yapılmıştır. Önerilen yöntem veri setindeki görüntülere uygulanmış ve Tablo 1'de verilen değerlere göre sistem performansı görsel ve sayısal olarak değerlendirilmiştir.

BT görüntülerindeki böbrek taşlarının konumlarının, sınırlarının ve sayılarının görsel olarak incelenmesi, önerilen yöntemin başarımının test edilmesi için gereklidir. Örnek bir abdominal BT görüntüsü Şekil 7'de verilmiştir. Önerilen yöntemle bulunan böbreklerdeki taşların sayısı kullanıcıya bilgi vermek için yazılmış ve taşların sınırları görüntü üzerinde çizdirilmiştir. Şekil 7'de verilen görüntü incelendiğinde böbrekte bulunan taşların sayılarının ve sınırlarının önerilen yöntem ile başarılı bir şekilde bulunduğu görülmektedir.

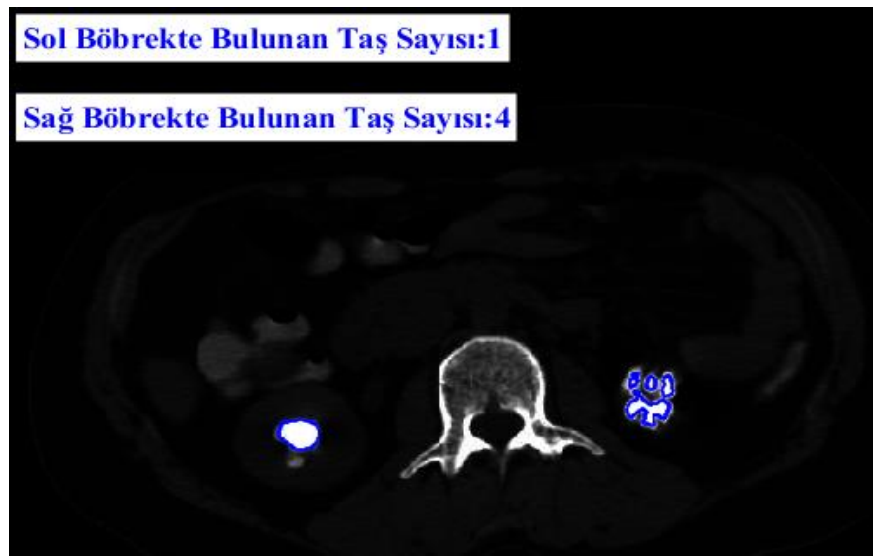

Şekil 7. Önerilen yönteme göre bulunan taşların sayısı ve sinırları
Yapılan çalışmada böbreklerin ve böbrekte bulunan taşların merkez konumları bulunmuştur. Ayrıca bu konumlar arasındaki uzaklık Öklid Mesafesi kullanılarak hesaplanmıştır. Böbreklere ve taşlara ait ağırlık merkezlerinin işaretlendiği ve koordinat bilgilerinin verildiği örnek görüntü Şekil 8'de verilmiştir. Bu koordinat bilgileri ile hesaplanan Öklid Mesafesi $=33.518$ olarak bulunmuştur. Ayrıca taşın piksel temelli alanı 306 olarak hesaplanmıştır.

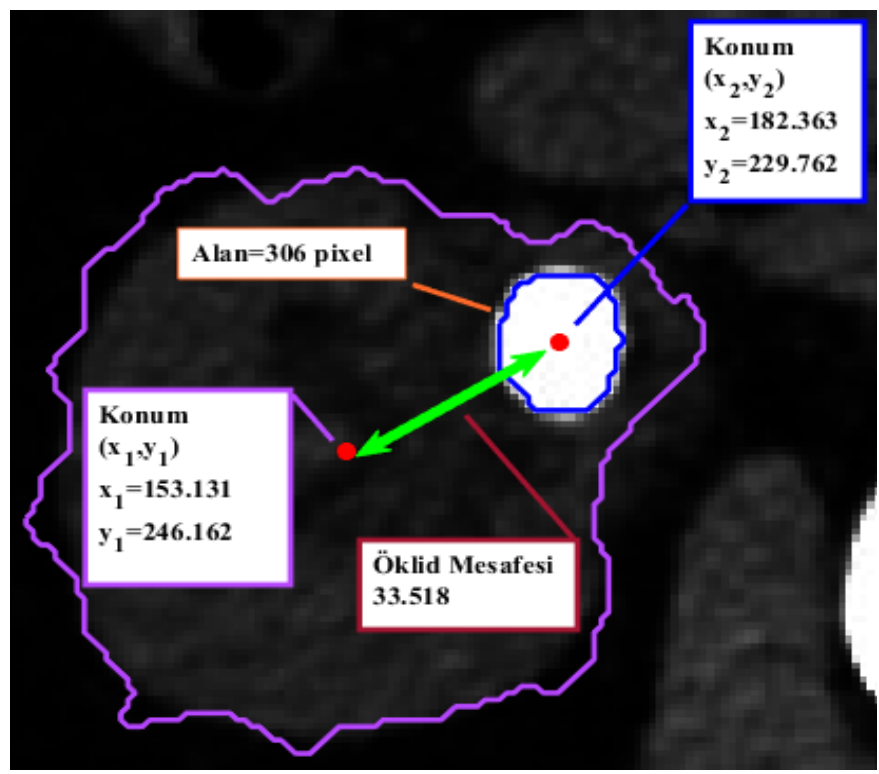

Şekil 8. Böbrek ve taşlara ait ağırlık merkezleri ve bu merkezler arasındaki Öklid Mesafesi

Çalışma sonuçlarının performans değerlendirmesinde hata matrisi kullanılmıştır [11]. Görsel incelemede sağ böbrekte 21 ve sol böbrekte 23 olmak üzere toplam 44 taş belirlenmiştir. Algoritma sonucu tahmin, görsel inceleme sonucu gerçek olmak üzere aşağıda verilen tanımlara göre hata matrisi oluşturulmuştur.

- $\quad$ True Positive (TP): Böbrekte taş varsa ve algoritma tarafından da taş var olarak etiketleniyorsa bu sonuç doğru pozitiftir.

- $\quad$ True Negative (TN): Böbrekte taş yoksa ve algoritma tarafından da taş yok olarak etiketleniyorsa bu sonuç doğru negatiftir.

- $\quad$ False Negative (FN): Böbrekte taş varsa ve algoritma tarafından taş yok olarak etiketleniyorsa bu sonuç yanlış negatiftir.

- $\quad$ False Positive (FP): Böbrekte taş yoksa ve algoritma tarafından taş var olarak etiketleniyorsa bu sonuç yanlış pozitiftir.

Önerilen yöntemde $T=200$ ve $\gamma=3$ değerleri seçilerek görüntü iyileştirilmiş ve bu görüntülere morfolojik işlemler uygulanarak taşlar hakkında sonuçlar (taş var/yok) elde edilmiştir. Hata matrisi için verilen tanımlara göre TP, TN, FP, FN değerleri hesaplanarak Tablo 2 oluşturulmuştur. Burada doğru pozitif sayısı $T P=42$, yanlış pozitif sayısı $F P=0$, doğru negatif sayısı $T N=15$ ve son olarak yanlış negatif sayısı $F N=2$ şekline hesaplanmıştır. 
Tablo 2. Hata matrisi

\begin{tabular}{ccccc}
\hline \multicolumn{5}{c}{ TAHMIN } \\
\hline & YOK & VAR & TOPLAM \\
\hline & YOK & TN=15 & FP=0 & 15 \\
$\frac{⿱ 䒑}{0}$ & VAR & FN=2 & TP=42 & 44 \\
& TOPLAM & 17 & 42 & 59 \\
\hline
\end{tabular}

Hata matrisindeki sonuçlara göre doğruluk, hassasiyet ve özgüllük değerleri sırası ile Denklem (5), (6) ve (7) kullanılarak hesaplanır.

$$
\text { Doğruluk }=\frac{T N+T P}{T N+T P+F N+F P} \times 100
$$

$$
\text { Hassasiyet }=\frac{T P}{F N+T P} \times 100
$$

$$
\text { Özgüllü } k=\frac{T N}{F P+T N} \times 100
$$

Performans analizi için oluşturulan hata matrisi gerçekte olan değerler ile algoritma sonucunda elde edilen değerlerin karşılaştırılması ile oluşturulmuştur. Gerçekte toplam taş sayıs1 44, algoritma ile tahmin edilen taş sayısı 42 'dir. Hata matrisinde verilen değerler Denklem (5), (6) ve (7)'de yerlerine koyularak sirasıyla Doğruluk $=\% 97$, Hassasiyet $=\% 96$, Özgüllü $\boldsymbol{k}=\% 100$ olarak hesaplanmıştır. Ayrıca morfolojik aşındırma ve genişletme işlemleri uygulanmadan önerilen çalışmanın performansı test edilmiştir. Eşik seviyesi aynı kalmak koşulu ile ( $T=$ 200) önerilen yöntemin performans parametreleri sirasıyla, Doğruluk $=\% 93$, Hassasiyet $=\% 95$, Özgüllük= \%88 bulunmuştur. Morfolojik işlemlerin uygulanması ile algoritma performansı artmıştır. $\mathrm{Bu}$ sayede önerilen yöntemin, görüntüyü değerlendirecek uzmana kolaylık sağlaması beklenmektedir.

\section{Tartışma}

$\mathrm{Bu}$ çalışmada abdominal BT görüntülerinde böbrek taşlarının yerlerinin tespiti, sınırlarının belirlenmesi, etiketlenmesi ve sayılması amaçlanmıştır. Görüntü ön işleme uygulamalarında sıklıkla kullanılan Gama Düzeltmesi görüntülerin netleştirilmesi ve gürültülerin giderilmesi için kullanılmıştır. Bu sayede böbreklerin kenar takibi doğru bir şekilde sağlanmıştır. Abdominal görüntülerde sadece böbrekler ile ilgilenildiğinden böbrek bölgeleri kullanıcı tarafindan ROI işlevi ile seçilmiştir. Gri seviyedeki böbrek görüntülerine belirlenen eşik değeri uygulanarak ikili görüntü olușturulmuş ve taşların ağırlık merkezi konumları, alanları ve sınırları tespit edilmiştir. Taş sınırları ve sayılarının daha iyi belirlenebilmesi için Morfolojik işlemler uygulanmıştır. $\mathrm{Bu}$ sayede görüntüde taş olmayan küçük nesneler yok edilmiş, bitişik taşlar ayrıştırılmış ve daha doğru bir taş sayımı gerçekleştirilmiştir. Belirlenen performans kriterlerine göre önerilen yöntem, taşların sayılarını ve sınırlarını başarılı bir şekilde bulmaktadır. Çalışma geliştirilmeye ve ilerlemeye açıktır. Örneğin kullanıcı müdahalesinin asgari düzeyde olduğu otomatik bir sistem geliştirilebilir. Buradan hareketle çalışmanın ilerleyen aşamalarında böbrek bölgelerinin otomatik bulunması için gerekli yöntemlerin incelenmesi ve uygulanması planlanmaktadır.

\section{Çıkar çatışması}

Yazarlar çıkar çatışmasının olmadığını beyan etmektedir.

\section{Benzerlik oranı (iThenticate): \%13}

\section{Kaynakça}

[1] N. Thein, H. A. Nugroho, T. B. Adji, and K. Hamamoto, An image preprocessing method for kidney stone segmentation in CT scan images. International Conference on Computer Engineering, Network and Intelligent Multimedia (CENIM), pp. 147-150, 2018.

[2] W. Kittanamongkolchai etc., The Changing Incidence and Presentation of Urinary Stones Over 3 Decades, Mayo Clinic Proceedings, 291-299, 2018. https://doi: 10.1016/j.mayocp.2017.11.018.

[3] T. Shah and S. Kadge, Analysis and identification of renal calculi in computed tomography images. International Conference on Nascent Technologies in Engineering (ICNTE), pp. 1-4, Navi Mumbai, India, Ocak 2019.

[4] S. Ebrahimi and V. Y. Mariano, Image quality improvement in kidney stone detection on computed tomography images. institute of computer science. University of the Philippines Los Baños, Laguna, Philippines. JOIG, 3 (1), 2015. https://doi: 10.18178 /joig.3.1.40-46.

[5] Dr. P. Akkasaligar, S. Biradar, and V. Kumbar, Kidney stone detection in computed tomography images. International Conference On Smart Technologies For Smart Nation (SmartTechCon), pp. 353-356, Bengaluru, India 2017.

[6] M. Deger ve İ. A. Aridogan, Perkutan nefrolitotomide komplikasyonlar ve yaklaşım. Çukurova Anestezi ve Cerrahi Bilimler Dergisi, 2 (2), 2019. https://dergipa rk.org.tr/tr/pub/jocass/issue/48421/605065

[7] Medullary Sponge Kidney https://radiopaedia.or/case s/medullary-sponge-kidney-8?lang=us, Accessed 17 January 2021.

[8] M. Sahnoun, F. Kallel, M. Dammak, C. Mhiri, K. Ben Mahfoudh, and A. Ben Hamida, A comparative study of MRI contrast enhancement techniques based on Traditional Gamma Correction and Adaptive Gamma Correction: Case of multiple sclerosis pathology. 4th International Conference on Advanced Technologies for Signal and Image Processing (ATSIP), pp. 1-7. Sousse, Mar. 2018.

[9] Rafael C. Gonzales and Richard E. Woods, Digital Image Processing, 2014. 
[10] S. Çınar and M. N. Kurnaz, Segmentation of medical images by using k-NN classifier on Field Programmable Logic Array (FPGA). National Conference on Electrical, Electronics and Computer Engineering p.5 Bursa, Turkey, 2010.

[11] S. Çınar, Design of an automatic hybrid system for removal of eye-blink artifacts from EEG recordings, Biomedical Signal Processing and Control. c. 67, s.
102543, May. 2021, https://doi: 10.1016/j.bspc.20 21. 102543.

[12] MedPix https://medpix.nlm.nih.gov/home Accessed 14 May 2021.

[13] Articles Radiopaedia https://radiopaedia.org/encyclo paedia/all/all?lang=us, Accessed 14 May 2021. 